\title{
Subjetividade e Ensino de Ciências: uma discussão sobre sexualidade na escola através do olhar docente
}

Roberto Sobreira Pereira Filho robertopereirafilho@yahoo.com 0000-0002-0710-3593

Fundação Oswaldo Cruz - Brasil

Isabela Cabral Félix de Sousa isabelacabralfelix@gmail.com 0000-0003-3104-0307

Fundação Oswaldo Cruz - Brasil

\section{RESUMO}

Este trabalho pretende refletir sobre o papel da subjetividade de professores de Ciências e Biologia durante o desenvolvimento do tema transversal denominado "Orientação Sexual" pelos Parâmetros Curriculares Nacionais do Ministério de Educação do Brasil. Um estudo de tipo etnográfico foi realizado durante um período de um ano e meio numa instituição federal de ensino localizada na cidade do Rio de Janeiro através de observação participante e entrevistas intensivas com todos os oito professores que compunham sua equipe de Ciências e Biologia. Os resultados apontam tanto para a importância de uma relação de confiança entre professores e alunos na condução do tema como também para a influência de tensões geradas por responsáveis de estudantes e colegas docentes sobre a discussão de conceitos relacionados à sexualidade na escola pesquisada.

PALAVRAS-CHAVE: Ciências (Ensino Fundamental). Educação Sexual. Etnologia 


\section{SITUANDO O PROBLEMA}

A presença da subjetividade nas ações de ensino e aprendizagem, mesmo reconhecida frequentemente como constituinte inexorável do processo pedagógico, costuma ser uma questão periférica na maioria dos trabalhos que se apresentam sobre a escola (HARGREAVES, 1998; ZEMBYLAS, 2003; LEITE, 2008; MEIROVICH, 2012). Pensando especificamente no desenvolvimento do campo de pesquisa de Ensino de Ciências, o qual alguns autores acreditam ter se institucionalizado no início da década de 1980 (GIL-PÉREZ, 1996, p.891), muita atenção tem se concentrado sobre o estudo dos conceitos científicos e sua interpretação pelos estudantes, resultando numa escolha de foco que pode explicar o pouco espaço para a reflexão sobre como as pessoas que convivem na escola participam de suas atividades. O programa de pesquisa sobre as concepções alternativas, por exemplo, embora tenha contribuído muito com o desenvolvimento das pesquisas sobre Ensino de Ciências também teria concentrado atenções para aquela problemática específica, dificultando reflexões sobre a escola enquanto local social e relegando um papel secundário para a subjetividade discente e docente na maioria dos trabalhos (MORTIMER, 2002, p.27; CHARLOT, 2010, p.149-151).

Ainda que de maneira tímida, contudo, o estudo da escola enquanto organização social complexa ocorre há algum tempo em campos de pesquisa como o das Ciências Sociais e Psicologia. Desde aproximadamente a década de 1960 a escola é objeto de pesquisas visando à compreensão do seu funcionamento, embora através uma lógica quantitativa muito diferente daquelas que embasam a maioria dos estudos mais recentes. Através de pesquisas que buscavam compreender a relação entre materiais de entrada (input) e resultados produzidos (output), os primeiros olhares sobre a escola a encaravam como uma caixa-preta cuja participação dos sujeitos no processo era menos importante que entender o manejo dos seus recursos (PACHECO, 2008, p.19). Tais estudos acabaram resultando num diagnóstico pessimista sobre o papel da escola, e a análise de teóricos contemporâneos como Bourdieu e Passeron apontava para um cenário de crise dos sistemas educacionais em vista de uma suposta ineficiência escolar em reduzir a desigualdade social. A insatisfação de alguns autores com a ideia que as escolas não traziam diferenças substanciais na realidade de seus alunos levou a uma revisão metodológica que abriu lacunas até então inexistentes para a investigação etnográfica e estudos de caso na tentativa de compreensão das práticas escolares; métodos qualitativos passaram assim a permear alguns estudos educacionais a partir da década 1970 em diante (FARIA FILHO et al, 2004, p.141). No sentido de compreender como professores e alunos participavam do processo, conceitos como "efeito-escola", "efeito-professor", "clima" e "cultura" escolar, por exemplo, surgiram como alternativas de combate ao fatalismo presente na ideia da escola como reprodutora das desigualdades sociais, juntando-se a novas ferramentas de análise nas pesquisas sobre ensino e educação (BRESSOUX, 1994, p.113; ALVES e SOARES, 2007, p.28).

Além de deslocar o foco dos resultados da escolarização para o processo em si, as pesquisas qualitativas sobre a escola trouxeram também uma inédita atenção à subjetividade dos atores envolvidos no processo pedagógico. Enquanto no Brasil grande parte dos estudos com esta temática utiliza o termo "afetividade" (LEITE, 2006), muitos autores internacionais se referem especificamente às "emoções" docente e discente (HARGREAVES, 1998; DAY e LEITCH, 2001; ZEMBYLAS, 2003; 
O'CONNOR, 2008). Independente dos termos utilizados o objetivo destes estudos é praticamente o mesmo: entender como subjetividades, expressas através de emoções e sentimentos de alunos e professores, participam do processo de ensino e aprendizagem que ocorre na escola.

\section{CURRÍCULO, SEXUALIDADE E ENSINO DE CIÊNCIAS}

A discussão sobre o tema "sexualidade" na escola se encontra atualmente ligada aos Parâmetros Curriculares Nacionais (PCNs) criados pelo Ministério da Educação do Brasil no final do século passado. Sob o título de "Orientação Sexual", um dos temas transversais ${ }^{1}$ associados a "questões sociais urgentes" (BRASIL, 1998a, p.65), os PCNs enfatizam a atenção à sexualidade por conta da "grande importância no desenvolvimento e na vida psíquica das pessoas, pois, além de sua potencialidade reprodutiva, relaciona-se com a busca do prazer, necessidade fundamental das pessoas" (BRASIL, 1998b, p.295). Entendendo que a exposição de conteúdos relacionados à reprodução humana dentro do currículo das ciências naturais é insuficiente para a exploração do assunto, os PCNs sugerem uma abordagem de forma transversal, contemplando assim as diversas áreas de conhecimento que representam as disciplinas escolares.

A posição dos $\mathrm{PCN}$ s sobre a discussão da sexualidade na escola reflete em suas entrelinhas a complexidade do assunto. A conduta sexual humana não é apenas uma atividade de foro íntimo, como pode parecer a uma primeira vista: à coletividade social se devem questões como controle da natalidade, crescimento demográfico, viabilidade dos descendentes e também doenças associadas à transmissão pelo sexo, elementos que configuram a discussão na seara da saúde pública. A gravidez adolescente, por exemplo, há muitos anos é encarada como um foco de investimento político visando a administração do comportamento sexual jovem, situação que põe a escola no meio de interesses que extrapolam as questões acadêmicas tradicionalmente atribuídas a si (ALTMANN, 2003, p.285). Tal situação leva pesquisadores como Patias e Dias (2011, p.42) a enfatizarem que discussões envolvendo o comportamento sexual adolescente não podem perder de vista valores sociais referentes ao corpo, sexualidade e gênero, de maneira que a própria adoção dos métodos contraceptivos - um problema fundamental dentro desta temática - também está intimamente relacionada a estes fatores.

À revelia destas considerações, entretanto, é comum vermos delegada à escola uma expectativa ingênua sobre seu papel. Espera-se desta instituição a formação de indivíduos autodisciplinados e que realizem sua iniciação no sexo sem trazer problemas decorrentes de gravidezes indesejadas e/ou proliferação de doenças entre a população, como se a escolarização fosse uma solução simples para todo esse processo de descobrimento do corpo e sua inserção no mundo. Neste sentido, cabe observar que a escola se serve "de símbolos e códigos, ela afirma o que cada um pode (ou não pode) fazer, ela separa e institui. Informa o 'lugar' dos pequenos e dos grandes, dos meninos e das meninas" (LOURO, 1997, p.58). Em outras palavras, a discussão sobre sexualidade na escola envolve uma complexidade de fatores políticos, sociais e mesmo institucionais que participam do processo e não podem ser ignorados numa análise cuidadosa do seu desenvolvimento. 
Tradicionalmente delegada aos professores de Ciências e Biologia, a abordagem sobre sexo na escola em grande parte das vezes é realizada através de uma perspectiva biologizante diferente daquela sugerida pelos PCNs e pesquisadores do tema, concentrando atenções em características anatômicas e fisiológicas dos aparelhos reprodutores masculino e feminino (ALTMANN, 2003; JARDIM e BRÊTAS, 2006; MAISTRO, 2006). Conquanto alguns pesquisadores apontem para problemas envolvendo a formação docente e/ou a maneira como o sexo é estruturado no currículo das ciências naturais, contribuindo para isso a tendência observada nos livros didáticos em apresentá-lo com foco principal em características biológicas da reprodução (ALTMANN, 2003, p.300); outros pesquisadores também enfatizam problemas particulares dos docentes, como resistência ou dificuldade pessoal na abordagem do assunto (JARDIM e BRÊTAS, 2006 , p.160). Por outro lado, pressões de pais ou outros membros da comunidade escolar também são frequentes, uma vez que a discussão sobre sexualidade está ligada de maneira inevitável a questões de preconceito, religião e outros tabus, fazendo de tensões e conflitos um lugar comum na discussão sobre comportamento sexual na escola (MAISTRO, 2006, p.184).

Como reconhecem os Parâmetros Curriculares Nacionais em sua avaliação sobre o lugar da Orientação Sexual dentro das escolas - "Assim como a inteligência, a sexualidade será construída a partir das possibilidades individuais e de sua interação com o meio e a cultura" (BRASIL, 1998b, p.296) - personalidades, visões de mundo e experiências de vida têm papel fundamental na discussão sobre sexualidade. Ignorar tais fatores dentro da experiência pedagógica é mais que desconhecer o que acontece dentro de uma sala de aula: é também acreditar que professores e alunos interagem maquinalmente entre si e o conteúdo que discutem, numa representação da experiência escolar que não corresponde à complexidade do mundo real e suas contingências. Dentro destas ponderações, portanto, é genuíno indagar: de que maneira tais questões participam do ensino de Ciências e Biologia, em particular dentro da discussão sobre sexualidade na escola? Como docentes e discentes, considerando suas disposições íntimas e visões desde sua própria subjetividade, lidam com o tema "sexualidade" durante o processo de ensino e aprendizagem?

\section{O DESENHO DA PESQUISA}

Considerando os obstáculos existentes na discussão sobre sexualidade na escola, bem como o referido problema da invisibilidade dos sujeitos através de seus papéis enquanto professores e alunos, este trabalho se propõe a refletir sobre a maneira como o tema transversal "Orientação Sexual" é desenvolvido pelos professores da equipe de Ciências e Biologia de uma instituição federal de ensino localizada na cidade do Rio de Janeiro ${ }^{2}$. A escolha do local deu principalmente por conta de sua importância no cenário da educação nacional, considerando seu papel enquanto laboratório no planejamento e execução de políticas públicas pela relação estreita que possui com o Ministério da Educação do Brasil. A investigação foi baseada principalmente no método chamado por Marli André (2005) etnografia da prática escolar, um estudo de tipo etnográfico que tem como foco questões relacionadas ao processo de ensino e aprendizagem que ocorre na escola. A etnografia da prática escolar consiste num misto de observação participante, entrevistas intensivas e análises de documentos, sendo um recurso profícuo para 
a compreensão das atitudes e significados implícitos nas expressões dos personagens presentes no ambiente escolar.

Além da observação participante realizada em aproximadamente 400 horas distribuídas por 101 dias entre julho de 2014 e dezembro de 2015, gerando um diário de campo com 239 páginas, também foram entrevistados todos os professores de Ciências e Biologia que compunham o quadro do colégio. Uma vez que o critério de seleção dos professores era ministrar aulas destas disciplinas, composta na ocasião por oito professores, toda equipe foi entrevistada. As entrevistas tiveram caráter semiestruturado e abordaram principalmente questões sobre ensino de Ciências e Biologia, prática docente e trajetória profissional, resultando um material de áudio de 8 horas e 10 minutos posteriormente transcrito em um texto de 270 páginas. Os docentes receberam para ser assinado e devolvido ao pesquisador antes das sessões de entrevista um Termo de Consentimento Livre e Esclarecido que, conforme resolução 196 de 1996 do Conselho Nacional de Saúde, Ihes assegurou privacidade de sua identidade, esclareceu os riscos a que estavam submetidos e também lhes garantiu retorno dos dados da pesquisa após sua conclusão. O roteiro das perguntas se encontra a seguir.

Apêndice I: Roteiro das perguntas realizadas aos professores durante as entrevistas

1.Nome, idade, residência. É ou já foi casado? Filhos?

2.Qual faixa de salários mínimos você e seu cônjuge recebem somados seus ganhos (1 a $5 ; 5$ a 10; 10 a $15 ; 15$ a 20; 20 a 25; 25 a 30; acima de 30)? Quantas pessoas moram com vocês?

3.Faz alguma atividade além de dar aula, profissionalmente ou não (esporte, artes, etc)?

4.Já teve outra profissão? Qual? Por quanto tempo?

5.Trabalha (ou trabalhou) como professor em outro local? Qual? Por quanto tempo?

6.Gosta de ser professor? Quais pontos positivos e negativos da profissão?

7.Há quanto tempo trabalha neste colégio?

8.Cite pontos positivos e pontos negativos de sua experiência no colégio. Quais suas impressões sobre a instituição? Como falaria dela para alguém que não a conhece?

9.0 que pensa da equipe do colégio (colegas professores e demais funcionários)?

10.O que pensa sobre o currículo de Ciências e Biologia?

11.Há algum conteúdo que goste mais de ensinar? Por quê?

12.Possui preferência por um nivel de escolaridade em especial para trabalhar? Por quê?

13.Percebe diferenças na sua exposição de aulas para turmas diferentes? Fale sobre.

14.Há turmas em que aprofunda mais algum conteúdo que em outras? Como explicaria esta diferença?

15.Qual importância da sua relação com os alunos para seu trabalho? Como lida com isso?

16.Qual o conteúdo, dentro do currículo de Ciências e Biologia, que você considera mais sensivel ao diálogo dentro de sala de aula?

17.Faça uma autocrítica da sua atuação enquanto professor(a).

18. Há alguma pergunta que você esperava que eu fizesse e não foi feita, ou algo que gostaria de ter dito e não disse? 
Após a transcrição das entrevistas este material somou-se ao diário de campo para ser analisado com base nas contribuições de Aguiar e Ozella (2006) e Bardin (2011) sobre a técnica de análise de conteúdo. De maneira geral estes autores entendem a análise de conteúdo como um conjunto de técnicas que utiliza procedimentos sistemáticos de descrição do conteúdo dos textos com interesse principal em inferir as condições de produção do discurso. Utilizando a mesma nomenclatura que Aguiar e Ozella (2006) para as unidades que formam as categorias de análise, foram formados três grupos hierarquicamente relacionados: o primeiro, dos chamados pré-indicadores, foi construído através de ideias que se apresentaram de maneira frequente nos textos ou tiveram relevância pela ênfase com que foram mencionados; o segundo grupo, dos indicadores, formou-se pela aglutinação destes pré-indicadores através principalmente da coerência e similaridade de temas; a terceira e última categoria, a dos núcleos de significação, reuniu os indicadores em um nível mais amplo que refletisse de maneira coerente os temas ali arranjados. Para a construção das categorias dos pré-indicadores e indicadores a análise se deu primeiro internamente dentro de cada grupo de dados apresentado: houve então uma análise específica das entrevistas dos professores e outra sobre o material do diário de campo; em seguida todos os pré-indicadores e indicadores reunidos a partir de cada um destes grupos foram tomados para formar em conjunto a categoria mais abrangente dos núcleos de significação que abarcasse todo o material produzido.

\section{RESULTADOS E DISCUSSÃO}

Embora o grupo de oito docentes que participou da pesquisa possuísse diferenças esperadas entre seus membros, como idade, sexo, tempo de magistério, escolaridade e nível de atuação (Fundamental e Médio), percebeu-se ao longo do trabalho uma homogeneidade refletida principalmente em suas atitudes e opiniões sobre o ensino de Ciências e Biologia e/ou sua prática enquanto professores. A diferença entre os níveis de atuação, por exemplo, ainda que ocorresse de fato durante os dois anos em que a pesquisa aconteceu, não refletia sua experiência geral: todos os professores que compunham o grupo à época já lecionaram para esses dois níveis fosse em outros anos trabalhados no colégio ou mesmo em outras instituições de ensino. Tal característica dos sujeitos pesquisados permitiu em algumas ocasiões que professores que estivessem atualmente lecionando para o Ensino Fundamental (três professores, do grupo de oito) reportassem situações ocorridas em aulas que ministraram para o Ensino Médio, e vice-versa.

Eu confesso que eu prefiro Ensino Médio. No Ensino Médio a matéria que eu mais gosto é Zoologia... Ecologia, que eu também gosto, é no terceiro ano (do Ensino Médio), mas... Zoologia, Botânica... sabe, essa parte de seres vivos, eu gosto muito disso. Agora, faixa etária acho que eu prefiro Ensino Médio mesmo. Assim, Oitavo Ano, que pego agora... eu acho que eu tenho uma relação boa com eles. Agora eu fico vendo outros professores no Sexto Ano (do Ensino Fundamental), eu vejo que eles saem esgotados, assim... eu fico assim, gente, eu saio das aulas do Oitavo Ano com dor na garganta! Eu estou com dor na garganta agora, entendeu?!? E eu fico pensando... imagina como seria no Sexto Ano! (trecho da entrevista com $\mathrm{P}^{3}{ }^{3}$ ) 
pública federal, local onde seus funcionários ingressam por concursos que são realizados com períodos de alguns anos de diferença. Há, assim, uma estabilidade no quadro docente que com o passar dos anos se converteu de uma relação profissional entre os docentes de Ciências e Biologia para uma amizade genuína, envolvendo inicialmente os membros mais antigos, mas também criando um clima receptivo para aqueles que porventura se integrassem à equipe.

Eu tenho a sorte de trabalhar, a minha equipe, tem essa sorte de ser pessoas assim, absolutamente excepcionais. E a gente tem uma troca muito grande, a gente consegue trocar e fazer esse intercâmbio. Já há muito anos atrás a gente tinha uma troca assim, olha $\mathrm{x}$, tá faltando isso, eles tão chegando sem saber isso, sem entender, por exemplo, um gráfico... "Deixa comigo!" e ele trabalhava, entendeu? Então a gente tem uma troca muito grande, é um microcosmo, temos essa sorte de ter uma equipe que funciona bem. Eu não sei se nos outros lugares a coisa funciona assim. Então, sem dúvida nenhuma, é uma vantagem sensacional que é única, é única (...). Na realidade, coisa que nunca aconteceu nos colégios que eu trabalhei, a gente acabou se tornando... nós somos amigos pessoais, né, de se frequentar, de viajar junto, nos tornamos amigos pessoais. Então sem dúvida nenhuma é uma vantagem única, porque a gente tá interagindo o tempo todo. Então a coisa funciona. (trecho da entrevista com P5)

Nenhuma outra equipe faz isso, de cobrir (faltas de colegas). A gente se cobre. Não tem professor? A gente faz horário extra, a gente se vira, porque a gente pensa muito no aluno. É uma coisa da equipe e que é legal manter isso, acho que é um compromisso. E o aluno fala isso. Ele diz: a equipe de Ciências e Biologia é a mais homogênea. Todo ano eu escuto isso do aluno, é impressionante. (trecho da entrevista com P7)

O senso coletivo e amizade aqui descritas por P5 e P7 talvez tenham sido as características mais evidentes observadas no grupo dos professores que participaram da pesquisa. Entretanto, conforme já mencionado, não apenas estas características aproximam o perfil dos docentes investigados, mas sobretudo sua maneira de enxergar e praticar o ensino de Ciências e Biologia.

A gente troca o tempo todo. Não é só pasta do Dropbox. É a interação. Olha a prova, pô, não gostei. Ih, essa questão tá... isso aqui não tá legal. Isso aqui... você tem certeza? E assim, dentro dos estilos próprios de cada um a gente tem uma troca, tanto que a gente vai ficando com uma cara. O pessoal fala, os alunos falam isso, assim, a equipe de Ciências e Biologia tem uma cara. Você pode pegar um prova e perceber que ela não foi feita pela nossa equipe. Porque a gente constrói uma identidade por conta desta articulação, dessa colaboração constante. (trecho da entrevista com P6)

Devido principalmente ao olhar homogêneo sobre o ensino de Ciências e Biologia dos professores abordados na pesquisa, que se iniciou com a proposta de investigar de maneira geral como a subjetividade docente e discente participa do processo pedagógico escolar, a investigação foi conduzida até o foco em que se detém o presente trabalho: unanimemente, o grupo enfatizou como um dos tópicos mais sensíveis ao diálogo em sala de aula aquele envolvendo questões relativas ao corpo e à sexualidade. Para chegar a este ponto específico, entretanto, vejamos como foram concebidas as categorias levantadas no estudo.

A análise das entrevistas com os professores formou 55 pré-indicadores e 14 indicadores, enquanto o diário de campo gerou 49 pré-indicadores e 9 indicadores. Todas as unidades de análise e categorias criadas a partir das mesmas tiveram sua nomenclatura designada de maneira coerente com o conteúdo a que se referiam. 
Cada pré-indicador foi estabelecido a partir de ao menos duas referências textuais, fosse a transcrição da entrevista ou a análise do diário de campo. Uma vez que a quantidade de pré-indicadores levantada foi muito grande (104), por questões de espaço estes serão omitidos nesta exposição. No Quadro 1 podemos ver como os indicadores formaram os núcleos de significação, as categorias mais abrangentes que nortearam a interpretação dos dados da pesquisa.

Quadro 1: As categorias dos indicadores e núcleos de significação construídas a partir da análise do diário de campo e transcrição das entrevistas com professores. Na primeira

coluna estão representados os indicadores e na segunda coluna os núcleos de significação. Para facilitar a identificação de cada grupo os indicadores referentes aos professores estão em negrito enquanto aqueles formados a partir do diário de campo estão em itálico.

\begin{tabular}{|c|c|}
\hline Pontos positivos do colégio & \multirow{7}{*}{$\begin{array}{l}\text { Relações entre professores, alunos e o } \\
\text { contexto específico do colégio }\end{array}$} \\
\hline Problemas do colégio & \\
\hline $\begin{array}{l}\text { Características da equipe de trabalho como } \\
\text { ponto positivo }\end{array}$ & \\
\hline Referências ao clima do colégio & \\
\hline Visões sobre a instituição escolar & \\
\hline Características do colégio & \\
\hline Características dos alunos & \\
\hline Considerações sobre o diálogo em sala & \multirow{4}{*}{$\begin{array}{l}\text { Relações entre professores, alunos e o } \\
\text { conhecimento em sala de aula }\end{array}$} \\
\hline Questões sobre a dinâmica da aula & \\
\hline Professor e a sala de aula & \\
\hline Alunos e a sala de aula & \\
\hline Discussão sobre valores no ensino & \multirow{6}{*}{$\begin{array}{l}\text { Relações entre professores, alunos e o } \\
\text { conhecimento em âmbito geral }\end{array}$} \\
\hline Proximidade com os alunos & \\
\hline Exposição de emoções e sentimentos & \\
\hline Atitudes do professor & \\
\hline Subjetividade e prática docente & \\
\hline Emoções do professor & \\
\hline $\begin{array}{l}\text { Questões sobre Orientação Sexual } \\
\text { (diário de campo) }\end{array}$ & \multirow{2}{*}{ Questões sobre Orientação Sexual } \\
\hline $\begin{array}{l}\text { Questões sobre Orientação Sexual } \\
\text { (entrevistas com professores) }\end{array}$ & \\
\hline Questões nevrálgicas & \multirow{3}{*}{$\begin{array}{l}\text { Relações entre professores, alunos e as } \\
\text { disciplinas Ciências e Biologia }\end{array}$} \\
\hline Sentido do ensino em Biologia & \\
\hline Professores e o ensino em Ciências e Biologia & \\
\hline $\begin{array}{l}\text { Questões sobre o magistério em Ciências e } \\
\text { Biologia }\end{array}$ & $\begin{array}{c}\text { Questões sobre o magistério em Ciências } \\
\text { e Biologia }\end{array}$ \\
\hline
\end{tabular}


A criação do núcleo de significação "Questões sobre Orientação Sexual", ocorrida através de parte destes pré-indicadores e indicadores exibidos acima, pode ser mais bem observada no Quadro 2 a seguir. Considerando que este é o núcleo de significação privilegiado para abordagem neste trabalho, os sete préindicadores que levaram a sua formação estão discriminados.

Quadro 2: O núcleo de significação construído a partir da análise das entrevistas de professores e leitura do diário de campo. Na primeira coluna estão representados os préindicadores, na segunda os indicadores e na última coluna o núcleo de significação. Para facilitar a identificação de cada grupo os pré-indicadores e indicadores referentes aos professores estão em negrito enquanto as categorias formadas a partir do diário de campo estão em itálico.

\begin{tabular}{|c|c|c|}
\hline $\begin{array}{c}\text { Orientação Sexual como tópico } \\
\text { sensível ao diálogo }\end{array}$ & \multirow{2}{*}{$\begin{array}{l}\text { Questões sobre } \\
\text { Orientação Sexual } \\
\text { (diário de campo) }\end{array}$} & \multirow{7}{*}{$\begin{array}{c}\text { Questões sobre Orientação } \\
\text { Sexual }\end{array}$} \\
\hline $\begin{array}{l}\text { abordagem do tema "Orientação } \\
\text { Sexual" precisa de confiança por } \\
\text { parte do aluno }\end{array}$ & & \\
\hline $\begin{array}{c}\text { abordagem transdisciplinar da } \\
\text { Orientação Sexual }\end{array}$ & \multirow{5}{*}{$\begin{array}{l}\text { Questões sobre } \\
\text { Orientação Sexual } \\
\text { (entrevistas com } \\
\text { professores) }\end{array}$} & \\
\hline $\begin{array}{c}\text { Orientação Sexual como tópico } \\
\text { polêmico }\end{array}$ & & \\
\hline $\begin{array}{l}\text { abordagem do tema } \\
\text { “Orientação Sexual” precisa de } \\
\text { confiança por parte do aluno }\end{array}$ & & \\
\hline $\begin{array}{l}\text { problemas envolvendo } \\
\text { sexualidade de alunos }\end{array}$ & & \\
\hline $\begin{array}{c}\text { demanda dos alunos por } \\
\text { assuntos envolvendo sexo e } \\
\text { drogas }\end{array}$ & & \\
\hline
\end{tabular}

A abordagem do tema "sexualidade" no colégio pesquisado, como ficou claro durante o processo de observação participante, é cercada de muito cuidado pelos professores de Ciências e Biologia. Isto ocorre principalmente devido à crença entre responsáveis pelos estudantes de uma suposta influência dos professores do colégio sobre a sexualidade dos alunos. Praticamente todos os professores que acumulam mais de 5 anos de serviços relatam algum entrevero pelo qual tiveram de passar por conta de colocações neste sentido feitas por algum responsável. Toda referência ao tema é feita sempre rodeada de explicações e atitudes defensivas, o que justificou a construção da categoria de pré-indicador "Orientação Sexual como tópico polêmico".

A gente não chega a falar de Educação Sexual, mas Sistema Reprodutor. Na reprodução acho que você tem que ter um diálogo aberto porque eles têm muita curiosidade, muita dúvida, e fazem muita besteira. Só vão falar se eles tiverem proximidade com o professor. Senão eles não vão falar. Não falam. (trecho da entrevista com P1)

O uso da expressão "Educação Sexual" pelo professor P1 chamou atenção durante a entrevista por ser uma expressão diferente daquela "Orientação Sexual" referida nos Parâmetros Curriculares Nacionais (BRASIL, 1998b, p.41). Os outros professores participantes da pesquisa tiveram o mesmo comportamento, nunca citando o termo como referido nos PCNs e alternando-se na maior parte das vezes entre "sexualidade" ou, como P1, "Educação Sexual". 
$\mathrm{R}^{4}$ - Tem algum tema, dentro do currículo de Ciências e Biologia, que você ache que seja mais sensível ao diálogo de vocês (professor e turma)?

P4 - Sexualidade. Disparado. Sexualidade; se você entra em aparelho reprodutor ou sexualidade humana... (...). (trecho da entrevista com P4)

Eu acho que a questão número um aí (falando sobre a importância de um bom diálogo com os alunos) é sexualidade. Corpo humano em geral. Porque ele precisava se sentir à vontade; ele precisa ter coragem de perguntar, não se sentir julgado, saber que o professor não vai achá-lo uma criatura de outro mundo. (trecho da entrevista com P7)

Existem questões muito polêmicas (no currículo de Ciências e Biologia). Evolução é uma delas. Origem da vida, quando você trabalha no primeiro ano com a Origem da Vida, é problemático... a questão da Educação Sexual é problemática... sem dúvida nenhuma são coisas muito delicadas. (trecho da entrevista com P5)

Tal atitude não ocorre ao acaso: o termo "Orientação Sexual" é, de fato, uma armadilha semântica, uma vez que é exatamente a mesma expressão utilizada nos campos de estudos da sexualidade e nos movimentos sociais, cujo significado remete à opção sexual do indivíduo (ALTMANN, 2003, p.284). Maistro (2006, p. 1620), por outro lado, reconhecendo que há confusão entre conceitos mesmo no campo de estudos sobre sexualidade, observa a existência de significados distintos para "Educação Sexual" e "Orientação Sexual": enquanto o primeiro estaria relacionado à transmissão de valores pela família, ambiente social e construção da sexualidade através da experiência cotidiana, ocorrendo por toda a vida, o segundo traria a proposta de ampliar, diversificar e aprofundar a visão do indivíduo sobre questões referentes ao sexo e à sexualidade, preenchendo lacunas de informação com o objetivo de desconstruir tabus e preconceitos estabelecidos. Para além da distância apontada entre os dois conceitos há também de se considerar o fato da "Educação Sexual" ter sido, durante anos, um item curricular presente nas escolas brasileiras - desde a década de 1960 muitas já a adotavam entre fluxos e refluxos de incorporação que ficavam em grande parte das vezes no nível do discurso e não da prática efetiva (ALTMANN, 2001, p.578). Desta forma, no caso de P1 e P5, tanto a intenção em distanciar-se da ideia de influência sobre a sexualidade dos alunos quanto a tradição escolar em citar "Educação Sexual" como o conjunto de conhecimentos relativos à sexualidade são possibilidades de explicações para o uso deste termo pelos professores no lugar de "Orientação Sexual", ainda que evitem na maior parte das vezes citar qualquer um dos dois. Neste sentido é também importante lembrar de Altmann (2003) e sua observação sobre os problemas que a adoção do termo "Orientação Sexual" possa vir a causar: o fato de sua interpretação literal sugerir um direcionamento da sexualidade, algo fora de propósito dentro da discussão pedagógica que se espera na escola, certamente é um desnecessário gerador de tensão.

Outra questão a se destacar na fala inicial de P1 é a correção que faz a si mesmo ao citar "Educação Sexual", dizendo não ser isto o que acontece no colégio e sim o ensino do "Sistema Reprodutor". Esta retificação chama atenção por dois motivos: 1) o cuidado que têm os professores ao se referirem a qualquer comentário sobre a abordagem de temas relacionados ao sexo e sexualidade; 2 ) a tendência de abordagem destes temas sob uma perspectiva biologizante, segundo ponto guarda coerência com alguns resultados de pesquisas sobre a 
Orientação Sexual nas escolas: como atentam alguns autores (ALTMANN, 2003; JARDIM e BRÊTAS, 2006; MAISTRO, 2006) é comum observar-se uma leitura da sexualidade exclusivamente a partir da visão da Biologia, ignorando ou negligenciando aspectos subjetivos e psicológicos inerentes ao tema. Assim, os autores apontam em suas pesquisas que professores naturalmente associam a abordagem da Orientação Sexual à exposição dos aparelhos reprodutores masculino e feminino, técnicas de contracepção e prevenção de doenças sexualmente transmissíveis, abordando pouco ou ignorando questões de gênero, preconceito e diversidade sexual, por exemplo, mesmo sendo estas orientações do Ministério da Educação através dos PCNs para a discussão do tema.

O distanciamento voluntário de P1 sobre a ideia de "Educação Sexual", porém, não traduz por si só a abordagem como é feita por ele ou por outros professores da instituição. Embora seja um tema muito controverso e sensível, nas entrelinhas da fala de P1 observamos outras questões não tão aparentes a partir de um olhar apressado. A seguir veremos um trecho que integra o pré-indicador "abordagem do tema 'Orientação Sexual' precisa de confiança por parte do aluno".

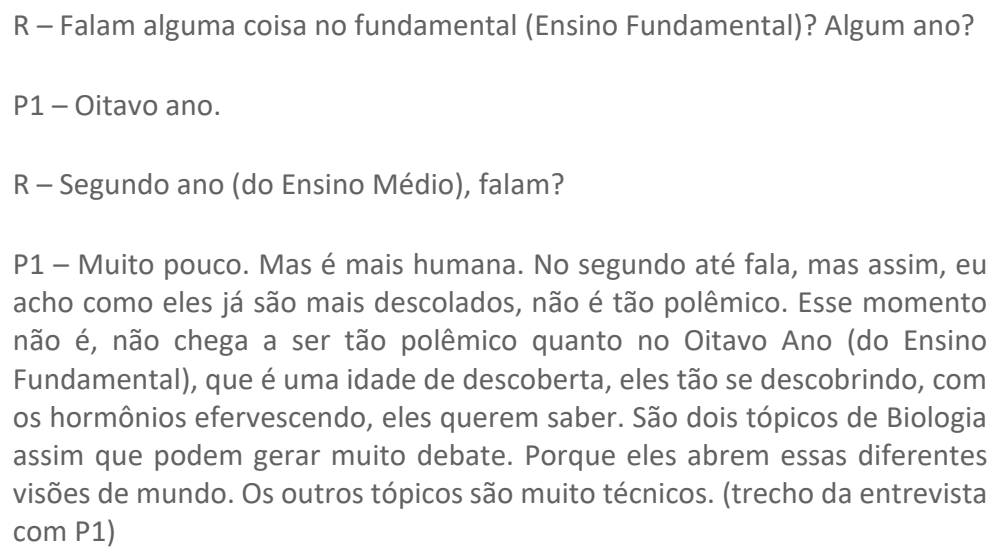
acho como eles já são mais descolados, não é tão polêmico. Esse momento não é, não chega a ser tão polêmico quanto no Oitavo Ano (do Ensino Fundamental), que é uma idade de descoberta, eles tão se descobrindo, com os hormônios efervescendo, eles querem saber. São dois tópicos de Biologia assim que podem gerar muito debate. Porque eles abrem essas diferentes visões de mundo. Os outros tópicos são muito técnicos. (trecho da entrevista com P1)

Ao explicar que o tema é "polêmico" no Oitavo Ano do Ensino Fundamental, quando os alunos "abrem essas diferentes visões de mundo", o professor P1 revela que suas aulas acabam não tratando somente do Sistema Reprodutor, como havia comentado num primeiro momento. Há motivos fortes para esta hesitação.

$R$ - Você falou que aqui se fala em Reprodução e não em Educação Sexual? Por quê?

P1 - Porque eu acho que existe uma crítica por parte de alguns grupos de pais que são contrários a esse tipo de debate na escola, que a Educação Sexual, a Orientação Sexual os pais ensinam em casa. Esse discurso já foi até proferido por alguns professores da casa em Conselhos de Classe, que não se pode debater a questão da sexualidade de aluno. Debate-se também se seria interessante ou não uma intervenção de um profissional para saber o que está acontecendo com a criança. Então existe um grupo de pais que é contra isso. Acho que é por isso que o departamento se preserva nesse sentido. Eu acho que existe sim esse debate, mas dentro do tópico Reprodução. Existe um debate sim, de gênero, de sexualidade, mas dentro de Reprodução.

$\mathrm{R}$ - Então é como se fosse uma coisa que tivesse que ficar mascarada?

Página | 331

P1 - É uma coisa que fica... ali.

R - Fica mascarada. 
P1 - Fica... fica mascarada. Tanto que ela não está no planejamento. Se você pegar o planejamento de Oitavo Ano (do Ensino Fundamental) vai ter Reprodução mas não tem essas questões. O máximo que aparece é contraceptivos e DSTs, no máximo. Outra é Caracteres Sexuais... mas assim, não aparecem essas questões nitidamente. Então vai muito do professor. Vai muito do professor trabalhar isso ou não.

R - Você acaba trabalhando porque você acha que é importante...

P1 - É. Eu trabalhei uma dinâmica muito básica com eles esse ano, assim. Quando fui trabalhar a questão Caracteres Sexuais Primários e Secundários, comecei a perguntar para eles: o que que é coisa de homem? O que que é coisa de mulher? Comecei a escrever no quadro. Comecei até a brincar: mas olha só, né, eu sou sentimental. Eu sou mulher, então? De acordo com a classificação de vocês? Então comecei a trabalhar essas coisas. Dúvidas, também. Não fiz esse ano mas ano que vem provavelmente vou fazer isso. A caixinha das dúvidas, para eles colocarem as perguntas e a gente ler. Até porque surge muita pergunta. Eles perguntaram mesmo, perguntaram muita coisa.

$\mathrm{R}$ - E a coordenação faz algum tipo de orientação em relação a isso? Do tipo: Ah, a gente aqui tá com um programa falando só de Reprodução, mas acho que é legal a gente conversar sobre sexo, falar sobre outras coisas.

P1 - Não houve essa orientação, pontuada, mas eu colocava pontos para coordenação e a coordenação sempre discutia comigo se achava viável ou não e por quê. Por exemplo: algo que eu pedi que foi rechaçado mas eu achei que pudesse ser interessante e, conversando com a coordenação, realmente, me mostrou talvez não fosse. Eu pensei em mostrar um vídeo de um parto. Que os meninos estavam perguntando muito como é que é e eu pensei em mostrar um vídeo de parto normal. Aí numa dessas conversas nas reuniões me falaram assim: ó, isso já tem história que causou trauma numa menininha, que é um pouco chocante a dilatação. Eu falei, não, então beleza, eu não vou mostrar. Isso pode dar problema com o pai, o pai pode vir reclamar; como é que você mostra pro meu filho um parto?!? Por mais que seja algo natural a gente tem que se preservar. Eu falei, não, tudo bem. (trecho da entrevista com P1)

O trabalho de campo revela certa coação sobre a condução dos professores na abordagem de ideias relativas ao sexo e sexualidade. É interessante que este direcionamento parece ocorrer não somente a partir de pais de alunos, mas também de colegas professores, estes últimos argumentando que "não se pode debater a sexualidade do aluno". Como explica P1, a equipe tenta se resguardar de possíveis problemas não abordando o tema de maneira explícita nem mesmo em seu planejamento. Isto não quer dizer que não o façam em algum nível: os professores trabalham nas suas aulas exatamente aquelas ideias que poderiam estar reunidas sob o conceito de Orientação Sexual, embora de maneira mais discreta e implícita. É uma forma tanto de cumprirem seu papel de professores quanto de se preservarem frente aos problemas com pais de alunos ou outros colegas. O trecho retirado do diário de campo (levantado como pré-indicador "abordagem do tema 'Orientação Sexual' precisa de confiança por parte do aluno") apresentado em seguida é um exemplo de como essa prática acontece.

Quando entrei em sala P7 estava falando exatamente sobre reprodução, especificamente do aparelho reprodutor feminino. Falava sobre o tabu que envolve a vagina, e como isso prejudicou a sexualidade feminina ao longo da 
Achei também muito interessante falar da sexualidade feminina e das questões que a envolvem, como a primeira vez para a mulher, o hímen, masturbação feminina, etc. O clima todo da aula foi extremamente agradável e descontraído. A turma comprou muito bem a ideia e fez diversas perguntas, absolutamente à vontade. Um aluno fez, inclusive, uma pergunta sobre homossexualidade. Aproveitando uma fala de P7 sobre hormônios, ele perguntou se os gays poderiam ter sua condição atribuída à quantidade de hormônios expostos durante a formação. A resposta de P7 me pareceu bem pertinente e atualizada, dizendo que não se pode considerar a sexualidade numa relação direta com os hormônios, muito menos se considerar a homossexualidade como consequência de um erro da natureza. O professor passou uns bons minutos falando sobre a questão, abordando uma série de pontos. Foi um exemplo claro e interessante da importância do feeling que devem ter os professores ao falar sobre esses temas. Os alunos aplaudiram P7 no fim da aula. (trecho do diário de campo, dia 17/03/2015)

A questão da abordagem do tema Orientação Sexual é muito delicada principalmente para os professores de Ciências e Biologia. Apesar de considerado um tema transversal, ou seja, que apresente possibilidades de discussão em todas as disciplinas do currículo escolar, historicamente são estes professores que acabam se responsabilizando em tratar do assunto, sendo exigidos num nível muito maior que seus colegas de outras disciplinas (ALTMANN, 2003, p.284). O que é comum se observar em outras escolas também se notou durante a observação participante nesta pesquisa: os professores de Ciências e Biologia são aqueles a quem os alunos recorrem para tirar dúvidas sobre temas relativos à sexualidade, colocando-lhes muitas vezes numa posição desconfortável em relação a estas pressões que alguns pais exercem sobre o direcionamento do tema colégio.

R - Isso (a pressão dos pais) coloca o professor de Ciências e Biologia numa posição muito delicada, né?

P1 - Sim! Muito ali... muito expoente. Na cara. Então a gente tem que se preservar nesse sentido, tem que tomar cuidado. Por exemplo, a gente tem vários casos aqui relatados de mães que não aceitam a opção sexual dos filhos e surtam. Hoje eu soube de uma. Que a mãe, pegando esse viés, que a mãe de um aluno do segundo ano (do Ensino Médio) descobriu que o filho é homossexual. O que a mãe fez? Revoltou-se, falou que vai trancar a matrícula, dizendo que a culpa é dos professores desse colégio. (silêncio) Trancou, vai trancar a matrícula e vai tirar o menino do colégio!

$R$ - Achando que o colégio que influenciou.

P1 - Achando que é influência da visão de mundo dos professores desse colégio. Vai trancar. Então realmente muitos pais têm essa visão, que a gente tem essa coisa meio que doutrinadora, essas políticas de esquerda, feminazi, essas coisas todas, e não é essa a ideia. A ideia é discutir as diferenças, as heterogeneidades. A realidade é isso, olha só, é esse monte de coisa acontecendo. Não dá para fechar os olhos e fingir que nada disso acontece, que isso não existe. (trecho da entrevista com P1)

Não houve aula na quinta-feira, dia 23/10, foi um dia de Conselho de Classe. Como não pedi autorização a tempo para a coordenação pedagógica, não participei. P7 me contou que houve uma pequena discussão com um professor de outra disciplina: depois de alguns professores comentarem sobre o caso de um garoto que não mais tem frequentado as aulas, aparentemente por problemas envolvendo sua opção sexual, este professor dissera que a escola não teria direito de fazer nenhuma interferência de orientação religiosa ou sexual, e que então deveria deixar a questão à família. P7 ressaltou que os professores debatiam no conselho sobre a necessidade 
de um acompanhamento do colégio para entender seu caso, o que não seria nenhuma "interferência", como alegava o professor contrário à proposta, mas tão somente o procedimento padrão em situações semelhantes. P7 disse que houve alguma repercussão e manifestações contrárias à fala do professor que se opôs, embora logo silenciadas pela coordenação pedagógica. Como não estive presente, fiquei apenas sabendo desta pequena descrição do evento. (trecho do diário de campo, dia 23/10/2014)

A situação apresentada aos professores de Ciências e Biologia do colégio é a seguinte: ou se evita ao máximo comentar questões relativas à sexualidade com seus alunos, poupando-se de problemas com os pais e/ou outros professores, negando suas próprias convicções profissionais e até mesmo diretrizes do próprio Ministério da Educação, ou se faz o que julga correto e se aguarda possíveis conflitos e queixas vindas dos indivíduos mais conservadores e reativos. De qualquer forma, seja por uma opção ou outra, o professor de Ciências e Biologia se encontra sempre sobre um caminho espinhoso, acumulando estresse e ansiedade em sua prática. Neste estudo, o que se observou na maior parte das vezes, contudo, é a atitude dos docentes em não negar suas conviç̧ões, prestando assistência aos alunos que os procuram discutindo questões relativas à sexualidade da forma que consideram a mais adequada possível.

\footnotetext{
Quando eu discuto Reprodução acho importante ir além do Sistema Genital e discutir a questão do gênero. E discutir a questão do preconceito. Por que que isso é de menino e isso é de menina? (...) Muitas vezes a escola é o único lugar que eles vão ter para conversar. A gente vê assim, muitos desses meninos aqui, eles conseguem ser eles mesmos na escola. Em casa eles não conseguem. Conversando com uma menina que foi minha aluna ano passado, uma menina que parece mais velha que os outros, acho que ela nem é mais velha, mas tem uma postura mais velha, mas séria, assim e tal, numa redação escreveu que gostava daqui porque aqui podia ser ela mesma. Em casa ela não pode ser ela mesma, sua família tinha uma pressão religiosa muito forte. (trecho da entrevista com P7)
}

Por conta da proximidade eles contam as coisas. Doenças na família, problemas de relacionamento, problemas sexuais, doenças sexuais, já participei de várias perguntas do tipo: e na primeira vez engravida? Eu tô com meu namorado, e a gente tá querendo. Então eu sento e explico, tem que ver isso, tem que ver aquilo, você já foi no ginecologista uma vez na vida? Esse tipo de coisa depende de uma cumplicidade e de uma proximidade (...). Por exemplo, peguei muitos anos sexto e nono (Anos do Ensino Fundamental), e mesmo não sendo temas desses anos eu acabava falando com eles sobre isso em outros ambientes fora de sala de aula. (trecho da entrevista com P6)

Os professores pesquisados reconhecem dramas familiares enfrentados por seus alunos e muitas das vezes, por conta do envolvimento que têm com estes no seu dia a dia, solidarizam-se com suas histórias dando todo o apoio que julgam necessário. Há uma relação de cumplicidade e companheirismo entre ambos, professores e alunos, formada por conta de sua convivência quase diária. Alunos procuram professores reconhecendo-Ihes como uma referência e se abrem aos mesmos muitas vezes como se fossem pessoas de sua família; por seu turno, os professores também acolhem alunos como se tratasse de fato de uma relação de sangue. O contexto afetuoso observado no colégio pesquisado possibilita que muitos alunos se sintam quase como num ambiente doméstico - às vezes até mais que isso, como citado no trecho acima - confortáveis em poder expressar-se da forma como julgam mais conveniente. Se a transição entre a infância e a 
adolescência é sempre um momento difícil, onde lugares e companhias inspiram constantemente sentimentos de reservas e inadequação, encontrar um local onde há pessoas que aceitam outras do jeito que se sintam melhor é como estar num verdadeiro oásis. Isto falando-se de adolescentes que se encaixam no padrão esperado pela sociedade; para aqueles que porventura apresentem alguma característica fora da norma, como os que se descobrem possuir uma inclinação afetiva diferente da heterossexual, por exemplo, o conforto descrito nesta situação toma proporções ainda maiores. O reconhecimento da diversidade humana e suas formas de ser e agir no mundo não deixa de ser um dos sentidos do ensino de Biologia no colégio, como se pode depreender da fala do professor P7: mais que falar exclusivamente da Fisiologia Reprodutiva, problematizar o gênero e levantar questões sobre o preconceito às escolhas de cada um é o que considera realmente importante a fazer enquanto docente de sua disciplina.

Além de concordarem que o sentido de sua disciplina deva levar algo a mais que uma simples exposição de conteúdos, os professores pesquisados entendem que para falar sobre sexualidade é fundamental ter uma boa relação com seus alunos. Como já havia sinalizado P1 no primeiro trecho desta seção, os alunos só participam da aula de fato caso sintam-se à vontade para isso; em contrário, a discussão fica restrita a uma exposição de tópicos sobre Reprodução Biológica.

Comecei reprodução, criei uns joguinhos para desenvolver com eles, eles fizeram uns joguinhos sensacionais. Mas teve um caso muito engraçado quando a gente começou a falar do corpo humano e vi que os meninos estavam com um revista pornográfica. Estavam no fundo da sala, cochichando... eu não aguento, então fui lá ver. Quando eu cheguei eles acharam que eu ia tomar. Eu falei: gente, material didático! Abre a roda aqui e vamos organizar. Vou ensinar pra vocês o nome certo. Porque ninguém conhece começar a vida sexual chamando periquito de meu loiro, não é? Aí eles começaram a rir. "Ah, não vai tomar?” Eu disse, não; a gente tem que olhar direito pra isso aqui, vamos conversar sobre isso aí que vocês estão vendo. Aí já perdeu a graça pra eles, que era estar olhando escondido. Ainda falei mais: aula que vem... foi do seu pai que você roubou ou foi do seu irmão? Negocia com quem foi porque na aula que vem eu quero aqui de novo pra gente continuar. Eles trouxeram! Entendeu a relação? (trecho da entrevista com P8)

Ter um bom vínculo com eles é fundamental para eles se abrirem e ao mesmo tempo não se perder a aula. Aí é o equilíbrio: se você é íntimo demais, a aula se perde. Que aí podem começar a falar da vida pessoal de alguém e outro vai falar ah, mas e o gay, ah, você é gay, hahaha... a aula se perdeu. Ou, se você é fechado demais, fica uma aula travada. Uma aula que eu vou falar do epidídimo, do testículo, etc. Fica tudo supertécnico e o que é técnico é complicado, porque vira uma questão de decoreba: então tá, o testículo, o epidídimo, a função é essa, tá ali, eu sei identificar no esquema... acabou. Mas quando você significa a questão... por que que eu tenho que saber disso? Por que que eu tenho... vasectomia, um dia você pode querer fazer uma vasectomia. Porque, ah, meu pai fez vasectomia... porque isso, isso e aquilo, ele é casado com a minha mãe, mas aí ele separou, então agora não pode mais ter filho. Mas é, pois é, então: pense nisso. Na sua vida, um dia se você optar por uma vasectomia, vai ser uma questão importante, você pensar... será que eu quero ter filhos no futuro? E como eles têm um vínculo aberto comigo, eles se permitem pensar e ir além da matéria. Ah, realmente, na minha vida isso pode ser importante. Ou, minhas falas, quando eles começam a entrar na bobeira, de sexo anal e outras piadinhas... eu tenho que intervir em prol da igualdade, assim, gente, sexo anal é um sexo possível. E quem é gay tem direito, e quem não é também, tem direito de usar o seu corpo como bem entender. Se for consensual ninguém tem nada a ver com isso. E tento 
os fazer saírem do besteirol e entrarem num ramo que eu quero, que é o ramo da reflexão, deles falarem, é, realmente... e aí esse aluno vira para mim o melhor possível, que é um ser humano crítico e construtor de uma realidade melhor. (trecho da entrevista com P4)

\begin{abstract}
Considerei curioso quando na sala dos professores P2 mencionou ter pedido para os alunos falarem apenas no nome das estruturas, não seus nomes vulgares. Pareceu-me restritivo. Sua postura durante a aula foi mais ou menos essa: falou como se estivesse falando de qualquer outra estrutura biológica do corpo humano, utilizando uma naturalidade aparentemente forçada. Os alunos também pareceram se comportar inicialmente como numa aula qualquer. Posso estar errado, mas eu diria que há desconforto em ambos os lados. Aos poucos algumas perguntas mais ousadas foram surgindo, como o que era, biologicamente, esse "estímulo" que o professor havia falado ser necessário para o pênis ficar ereto. Achei a aula um pouco barulhenta e confusa, envolvendo timidez de ambos os lados, professor e alunos. Em perguntas mais desengonçadas, P2 se aproxima dos alunos para respondêlos, de maneira a reduzir o seu constrangimento. A maioria esmagadora dos alunos, na maior parte do tempo, parecia estar bastante inibida com o tema, sem manifestar dúvidas mais importantes. O clima geral é de inibição e brincadeira.(trecho do diário de campo, dia 20/06/2015)
\end{abstract}

Ter um bom vínculo com os alunos é fundamental para significar a questão, de acordo com o professor P4; a experiência na aula de P2, onde houve uma espécie de "barreira" separando professor e alunos, foi um teste interessante para as próprias observações levantadas na entrevista com P4. Com alunos e professor pouco à vontade entre si, pouco se trabalhou na aula citada acima para o Oitavo Ano além de características anatômicas e fisiológicas dos aparelhos reprodutores masculino e feminino. Há que se dizer, contudo, que este evento não representou como o tema foi abordado na maioria das outras aulas da equipe. $O$ trabalho realizado pelos professores de Ciências e Biologia parece longe de ser uma abordagem fria e conteudística do tópico Reprodução, como o professor P1 sugeriu inicialmente: os docentes discutem uma série de questões com seus alunos, desde gênero e preconceito à ética de uma maneira mais ampla, ainda que possam ter como ponto de partida o conteúdo curricular anatômico e fisiológico tradicional. Cabe também ressaltar que P2 estava lidando com o Oitavo Ano do Ensino Fundamental - como havia dito anteriormente o próprio professor P1, é um momento em que há barreiras e complicações naturais para o desenvolvimento de discussões sobre sexualidade por conta da respectiva faixa etária, o que não deixa de ser um complicador para a exposição dos professores que lidam com esse nível.

\title{
CONSIDERAÇÕES FINAIS
}

Embora esta pesquisa possa apontar para uma ideia elementar - professores e alunos são seres humanos e suas personalidades participam do interesse ou desinteresse sobre determinados tópicos discutidos na escola - ainda são poucos os trabalhos que têm como foco a relação entre a subjetividade dos atores escolares e o processo de ensino e aprendizagem.

Além da percepção do ponto certo para abrir-se à turma num clima mais convidativo ao debate e reflexão - que Hargreaves $(1998$, p.838) entende tratarse do conceito de emotional understanding, a maneira pela qual docentes compreendem os sinais não verbais de seus pupilos - os professores também 
enfrentam problemas gerados por tensões que são externas ao espaço da sala de aula. Como ficou exposto através da entrevista com P1 ou no trecho tomado do diário de campo sobre considerações realizadas num conselho de classe envolvendo faltas de um aluno do colégio, há um clima tenso para a discussão sobre sexualidade nas aulas de Ciências e Biologia por conta de alguns responsáveis por alunos e colegas professores considerarem que tal abordagem não deva ser realizada na escola. Os professores das disciplinas Ciências e Biologia, historicamente responsáveis pela apresentação dos conceitos ligados à reprodução e sexualidade, sentem-se pressionados a não desenvolver as aulas da maneira que consideram ideal, situação que lhes causa estresse por se sentirem tolhidos em sua prática profissional. A estratégia utilizada pelos docentes passa então a ser a discussão do tema através de uma maneira velada: enquanto oficialmente considera-se a discussão do tema Reprodução Biológica, na prática em sala de aula os professores de Ciências e Biologia também discutem questões de gênero, preconceito, diversidade sexual e outras ideias caras à Orientação Sexual conforme recomendam os Parâmetros Curriculares Nacionais (BRASIL, 1998b). O que se observou em campo, portanto, foi algo sensivelmente diferente do que outros autores sinalizam sobre a prática de ensino em Orientação Sexual em escolas brasileiras, que ficaria restrita principalmente a aspectos técnicos e biologizantes do currículo (ALTMANN, 2003; JARDIM e BRÊTAS, 2006; MAISTRO, 2006). Para esta percepção foi fundamental a imersão realizada através do método de observação participante ao longo deste um ano e meio de trabalho em campo; um olhar precipitado provavelmente tomaria o desenvolvimento do tema somente como o mesmo é apresentado oficialmente, ou seja, uma exposição tecnicista da Fisiologia e Anatomia da Reprodução Humana. Cabe refletir se a observação referida por outros pesquisadores possa estar de fato representando o que acontece nas salas de aula brasileiras quanto à discussão do tema transversal "Orientação Sexual", algo que somente outros estudos em profundidade podem de fato atestar.

Outra questão importante que não pôde ser mais bem desenvolvida durante a pesquisa é compreender de que maneira as pressões exercidas por estes atores que não são professores de Ciências e Biologia e/ou estudantes possam estar participando da discussão sobre sexualidade nas escolas. Embora esta seja uma pergunta não contemplada por este trabalho, considerando que a percepção do problema se deu durante a própria investigação, a reflexão se apresenta oportunamente. É válido esperar que outras investigações aprofundem a compreensão sobre como a comunidade escolar - responsáveis, alunos e os próprios colegas professores - participam da discussão sobre sexualidade na escola, mesmo que de maneira involuntária e indireta. Este foi o caminho, por exemplo, de Lima (2013) em sua tese de doutorado, em que investigou professores de outras disciplinas (além de Ciências e Biologia), gestores escolares e inspetores para compreender a abordagem da sexualidade na escola pesquisada. Apesar dos docentes de Ciências e Biologia serem tradicionalmente responsáveis pela apresentação e desenvolvimento do tema, estes profissionais podem estar sendo excessivamente cobrados por uma discussão da qual não participam/desenvolvem sozinhos, trazendo uma desnecessária tensão para a sala de aula que interfere de maneira negativa sobre a discussão em torno do tema sexualidade na escola. De acordo com o que os dados produzidos permitem inferir, a subjetividade de cada professor e suas maneiras próprias ao encontrar-se entre estas tensões se relacionam de maneira direta com a forma como o tema transversal chamado 
pelos PCNs "Orientação Sexual” é desenvolvido na escola. Este foi o caso, por exemplo, da aula de P2 registrada no diário de campo, onde o aparente desconforto do professor se refletiu numa inibição da turma em que trabalhava; ou da entrevista de P8 que, de maneira diametralmente oposta, relatou um episódio em que se integrou à observação de uma revista masculina por seus alunos e a transformou num objeto de discussão.

Por fim, vale atentar para outros problemas que emergem a partir do tema intitulado pelos PCNs "Orientação Sexual". O Brasil vive um momento de discussão política em que termos como "ideologia de gênero" são divulgados pela mídia de massas como se representasse, em verdade, um conceito científico (AZEVEDO, 2015; NAGIB, 2015); em conjunto com esse fenômeno há um crescimento do conservadorismo e uma reação de determinados setores da sociedade ao que se considera uma "doutrinação homossexual" das escolas brasileiras sobre seus estudantes (BOLSONARO, 2016). Conquanto estas ideias sejam ventiladas por sujeitos que não participam ou estão ligados de alguma maneira às escolas, sendo ilegítimas no seu fundamento, sua repercussão não é pequena e pressiona não somente os professores de Ciências e Biologia, mas a própria escola, professores de outras disciplinas e sua proposta em desenvolver seu currículo da maneira como consideram mais adequada. 


\title{
Subjectivity and Science Education: a discussion about sexuality in school through the teacher's view
}

\begin{abstract}
This paper aims to highlight the role of subjectivity of teachers in discussions involving sexuality theme in Sciences and Biology's lessons. An ethnographic study was carried out over a period of one year and a half at a federal school located in the city of Rio de Janeiro, through participant observation and in depth interviews with the eight teachers who composed the Science and Biology school's team. The results point out to the importance of a relationship of trust between teachers and students to deal well with this theme as well as the influence of tensions generated by both student's parents and other school teachers on the discussion about sexuality concepts in the school researched.
\end{abstract}

Keywords: Science (Elementary School). Sexual Education. Ethnology 
${ }^{1}$ Osz outros temas transversais são Ética, Saúde, Meio Ambiente, Trabalho e Consumo e Pluralidade Cultural (BRASIL, 1998a, p.66-68).

${ }^{2}$ Este artigo apresenta parte da pesquisa de campo de uma tese de doutorado desenvolvida através do Programa de Pós-Graduação em Ensino em Biociências e Saúde do Instituto Oswaldo Cruz. Embora a tese tenha um escopo mais amplo e aborde as relações afetivas desenvolvidas entre discentes, docentes e conhecimento durante a experiência escolar, este trabalho tem como foco específico a forma como os professores lidam com as relações entre o tema "sexualidade" e o ensino de Ciências e Biologia.

3 Professores serão referidos através da letra "P" seguida de um número correspondente como forma de preservar sua identidade, compromisso assumido na ocasião do contato para as entrevistas.

${ }^{4} \mathrm{~A}$ letra " $\mathrm{R}$ " representa a fala do pesquisador durante a entrevista.

\section{REFERÊNCIAS}

AGUIAR, Wanda Maria Junqueira; OZELLA, Sérgio. Núcleos de significação como instrumento para a apreensão da constituição dos sentidos. Psicologia Ciência e Profissão, v.26, no2, 222-245, 2006;

ALTMANN, Helena. Orientação sexual em uma escola: recortes de corpos e de gênero. Cadernos Pagu, Campinas, v.21, p.281-315, 2003;

ALVES, Maria Teresa Gonzaga; SOARES, José Francisco. Efeito-escola e a estratificação escolar: o impacto da composição por nível de habilidades dos alunos. Educação em Revista, v.45, p.25-38, junho de 2007;

ANDRÉ, Marli Eliza Dalmazo Afonso de. Etnografia da prática escolar. $12^{\mathrm{a}}$ edição. Campinas: Papirus, 2005;

AZEVEDO, Reinaldo. Patrulha gayzista e feminazi chega ao Colégio Pedro II, uma instituição federal. Disponível em <http://veja.abril.com.br/blog/reinaldo/geral/patrulha-gayzista-e-feminazichega-ao-colegio-pedro-ii-uma-instituicao-federal/>. Último acesso em 26/06/2017;

BARDIN, Laurence. Análise de conteúdo. São Paulo: Edições 70, 2011; 
BOLSONARO, Jair. Entrevista do deputado federal Jair Bolsonaro concedida ao programa Esfera Pública da Rádio Guaíba. Porto Alegre: 26/01/2016. Disponível em <https://www.youtube.com/watch?v=IfVCuzvOPJo>. Último acesso em 26/06/2017;

BRASIL. Ministério da Educação. Parâmetros curriculares nacionais. Terceiro e quarto anos do ensino fundamental. Introdução aos parâmetros curriculares nacionais. Brasília: MEC, 1998a;

BRASIL. Ministério da Educação. Parâmetros curriculares nacionais. Orientação Sexual. Brasília: MEC, 1998b;

BRESSOUX, M. Pascal. Note de synthèse [Les recherches sur les effets-écoles et les effets-maîtres]. Revue française de pédagogie, v. 108, pp. 91-137, 1994;

CHARLOT, Bernard. Desafios da educação na contemporaneidade: reflexões de um pesquisador. Educação e Pesquisa, São Paulo, v.36, no especial, p.147-161. Entrevista concedida a Teresa Cristina Rego e Lucia Emilia Nuevo Barreto Bruno, 2010;

DAY, Christopher; LEITCH, Ruth. Teachers' and teacher educators' lives: the role of emotion. Teaching and Teacher Education v.17, p.403-415, 2001;

FARIA FILHO, Luciano Mendes de et al. A cultura escolar como categoria de análise e como campo de investigação na história da educação brasileira. Educação e Pesquisa, v.30, no1, p.139-159, jan/abr, 2004;

GIL-PÉREZ, D. New trends in science education. International Journal of Science Education, v.18, no8, p.889-901, 1996;

HARGREAVES, Andy. The emotional practice of teaching. Teaching and Teacher Education, v.14, no8, p.835-854, 1998;

JARDIM, Dulcilene Pereira; BRÊTAS, José Roberto da Silva. Orientação sexual na escola: a concepção dos professores de Jandira - SP. Revista Brasileira de Enfermagem, v.59, no2, p.157-162, 2006;

LEITE, Sérgio da Silva. Afetividade e Práticas Pedagógicas. In: (organizador). Afetividade e Práticas Pedagógicas. São Paulo: Casa do Psicólogo, 2006; 
LIMA, Ana Cristina Leal Moreira. Onde há poder há resistência: questões de gênero e sexualidade em uma escola carioca. Rio de Janeiro: Universidade Federal do Rio de Janeiro, 2013. 175 f. Tese (Doutorado em Educação em Ciências e Saúde). Programa de Pós-Graduação em Ciências e Saúde, Universidade Federal do Rio de Janeiro, Rio de Janeiro, 2013;

LOURO, Guacira Lopes. Gênero, sexualidade e educação: uma perspectiva pósestruturalista. $6^{a}$ edição. Petrópolis: Editora Vozes, 2003;

MAISTRO, Virginia lara de Andrade. Projetos de Orientação Sexual na escola: seus limites e suas possibilidades. Londrina: Universidade Estadual de Londrina, 2006. 243f. Dissertação (Mestrado em Ensino de Ciências e Educação Matemática). Programa de Pós-Graduação em Ensino de Ciências e Matemática, Universidade Estadual de Londrina, Londrina, 2006;

MEIROVICH, Gabriel. Creating a favourable emotional climate in the classroom. The International Journal of Management Education, v.10, no, p.169-177, 2012;

MORTIMER, Eduardo Fleury. Uma Agenda para a Pesquisa em Educação em Ciências. Revista Brasileira de Pesquisa em Educação em Ciências, [online], v.2, $\mathrm{n}$ 1, $\quad$ p.36-59, 2002. Disponível em https://www.researchgate.net/profile/Eduardo_Mortimer/publication/22859748 1_UMA_AGENDA_PARA_A_PESQUISA_EM_EDUCACAO_EM_CIENCIAS_2_A_rese arch_agenda_for_science_education/links/09e415137da702d8c8000000.pdf. Último acesso: 26/06/2017;

NAGIB, Miguel. A ideologia de gênero no banco dos réus. Disponível em <http://www.gazetadopovo.com.br/opiniao/artigos/a-ideologia-de-genero-nobanco-dos-reus-2jbsz8k92cse5z6f5721cc8f0>. Último acesso: 26/06/2017;

O'CONNOR, Kate Eliza. "You choose to care": Teachers, emotions and professional identity. Teaching and Teacher Education, v.24, p.117-126, 2008;

PACHECO, Marcella da Silva Estevez. Clima escolar nas escolas públicas municipais de alto e baixo prestígio no Rio de Janeiro - a percepção dos alunos sobre o ambiente escolar. Rio de Janeiro: Universidade Federal do Rio de Janeiro, 2008. 119 f. Dissertação (Mestrado em Educação). Programa de Pós-graduação em Educação, Universidade Federal do Rio de Janeiro, Rio de Janeiro, 2008;

PATIAS, Naiana Dapieve; DIAS, Ana Cristina Garcia. Fatores que tornam adolescentes vulneráveis à ocorrência de gestação. Adolescência e Saúde, v.8, no2, p.40-45, abr/jun 2011; 
ZEMBYLAS, Michelins. The emotional characteristics of teaching: an ethnographic study of one teacher. Teaching and Teacher Education, nำ20, p.185-201, 2003.

Recebido: 2016-12-21

Aprovado: 2017-07-10

DOI: $10.3895 /$ rbect.v10n3.5246

Como citar:

PEREIRA FILHO, R. S. SOUSA, I. C. F., Subjetividade e Ensino de Ciências: uma discussão sobre sexualidade na escola através do olhar docente. Revista Brasileira de Ensino de Ciência e Tecnologia, v. 10, n. 3, 2017. Disponível em: < https://periodicos.utfpr.edu.br/rbect/article/view/5246>. Acesso em: XXXXXX.

Correspondência: Roberto Sobreira Pereira Filho - robertopereirafilho@yahoo.com.

Direito autoral: Este artigo está licenciado sob os termos da Licença Creative Commons-Atribuição 4.0 Internacional. 